\title{
Internationaler Menschenrechtsschutz
}

\author{
Das Recht der EMRK und des IPbpR
}

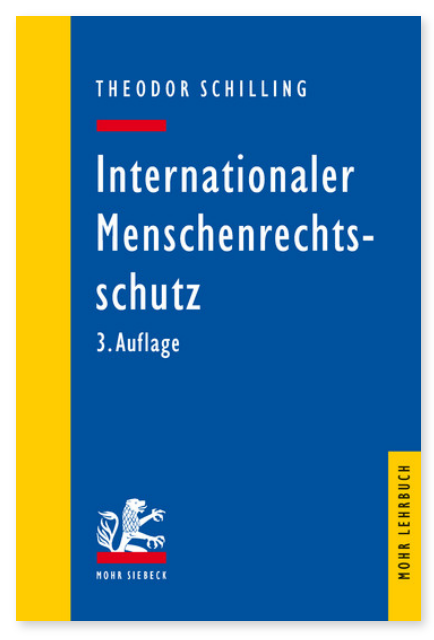

3., erweiterte und überarbeitete Auflage; 2016. XXII, 461 Seiten. MLB

ISBN 978-3-16-154794-2

DOI 10.1628/978-3-16-154794-2

eBook PDF $36,00 €$
Dieses Lehrbuch veranschaulicht das System des internationalen Menschenrechtsschutzes, wie es sich seit der Mitte des letzten Jahrhunderts entwickelt hat und wie es in Deutschland gilt.

Für die dritte Auflage hat Theodor Schilling das gesamte Werk gründlich überarbeitet und auf den aktuellen Stand der Rechtsprechung (31.12.2015) gebracht. Gänzlich neu konzipiert wurden die Abschnitte über die Zusicherung der

Menschenrechte durch die Vertragsstaaten sowie ihre Hoheitsgewalt, das Recht auf Leben, die Ausübung der Religion und die Fairness im Strafverfahren. Neu eingefügt wurden Abschnitte über den Menschenhandel und die Freiheitsentziehung im bewaffneten Konflikt.

Für Bibliotheken gelten bei diesem Titel abweichende Konditionen; bitte wenden Sie sich an den Vertrieb.

Keine aktuellen Daten verfügbar.

Jetzt bestellen:

https://mohrsiebeck.com/buch/internationaler-menschenrechtsschutz-9783161547942?no_cache=1

order@mohrsiebeck.com

Telefon: +49 (0)7071-923-17

Telefax: $+49(0) 7071-51104$ 